\title{
ST
}

Science \& Technology

PAPER - OPEN ACCESS

Skrining Fitokimia Dan Aktivitas Antimikroba Dari Tumbuhan Bangun-Bangun (Coleus Amboinicus Lour)

\author{
Author $\quad$ : Rosliana Lubis dkk., \\ DOI $\quad: 10.32734 /$ st.v2i1.322 \\ Electronic ISSN $\quad: 2654-7082$ \\ Print ISSN : :2654-7074
}

Volume 2 Issue 1 - 2018 TALENTA Conference Series: Science \& Technology (ST)

This work is licensed under a Creative Commons Attribution-NoDerivatives 4.0 International License.

Published under licence by TALENTA Publisher, Universitas Sumatera Utara

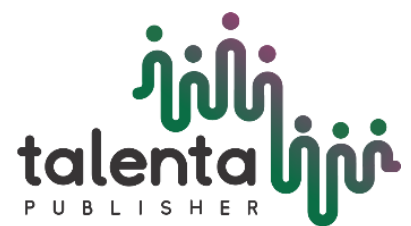




\title{
jibli talentalioi \\ TM Conference Series 02 (2019)

\section{Skrining Fitokimia Dan Aktivitas Antimikroba Dari Tumbuhan Bangun-Bangun (Coleus Amboinicus Lour)}

\author{
Rosliana Lubis ${ }^{\mathrm{a}, \mathrm{b}^{*}}$ \\ ${ }^{a}$ Departemen Kimia, Fakultas Matematika dan Ilmu Pengetahuan Alam Universitas Sumatera Utara, Medan \\ ${ }^{b}$ Fakultas Biologi Universitas Medan Area \\ roslianalubis@staff.uma.ac.id
}

\begin{abstract}
Abstrak
Penelitian ini bertujuan untuk mengekstraksi, skrining fitokimia, dan analisa aktivitas mikroba dari daun bangun-bangun dengan menggunakan pelarut etil asetat $70 \%$ dan n-heksan. Metode ekstraksi menggunakan metode maserasi. Komposisi kimia senyawa aktif yang diuji terdiri dari alkaloid, flavonoid, terpenoid, tanin, dan saponin. Aktivtias antimikroba ekstrak etil asetat $70 \%$ dilakukan menggunakan metode pengukuran luas zona hambat. Bakteri uji yang digunakan terdiri dari E. Coli ATCC 25922 dan Pseudomonas aeruginos. Uji aktivitas bakteri dilakukan bersifat invitro. Pengukuran zona hambat menggunakan variasi konsentrasi ekstrak etil asetat $70 \%$ terdiri dari $0 \%, 15 \%, 30 \%, 45 \%, 60 \%$, dan $75 \%$ (v/v).

Hasil Penelitian :menunjukkan bahwa ekstrak etil asetat $70 \%$ daun Handeuleum secara kualitatif teridentifikasi memilki kandungan senyawa kimia alkaloid, Flavonoid, Terpenoid, Steroid, Tanin, dan Saponin. Aktivitas bakteri E. Coli ATCC 25922 dan Pseudomonas aeruginosa terhadap ekstrak didasarkan kepada pengukuran luas zona hambat yang terbentuk. Luas zona hambat yang terbentuk dari ekstrak etil asetat daun Handeuleum dengan range konsentrasi $0 \%$ s.d $75 \%$ terdiri dari $9,50 \mathrm{~mm}-21,2 \mathrm{~mm}$ dan $9,00 \mathrm{~mm}-20,6 \mathrm{~mm}$
\end{abstract}

Kata Kunci: ekstrasi etil asetat; skrining fitokimia, aktivitas mikroba; E.coli; Pseudomonas aeruginos;

\section{Pendahuluan}

Tanaman obat. Secara etnobotani, Handeleum dengan nama ilmiah (Graptophyllum pictum L. Griff.) merupakan salah satu tanaman obat Sumatera utara yang memiliki khasiat sebagai obat. Oleh masyarakat pesisir di Mandailing Natal rebusan air c dipercaya dapat menyembuhkan diare.Ada juga yang mempercayai daun $\mathrm{c}$ ini sebagai obat luka.Penggunnaannya dilakukan dengan melumatkan daun tersebut dan menempelkannya kebagian tubuh yang luka.

Daun Hendeleum tanaman yang dapat ditemukan dari dataran rendah hingga pegunungan dengan ketinggian 1.250 mdpl. Morfologi tanaman Handeleum adalah berbentuk perdu atau pohon kecil, dengan tinggi 1,5 - $3 \mathrm{~m}$, batang berkayu, kulit dan daun berlendir dan baunya kurang enak, cabang bersudut tumpul, berbentuk galah dan beruas rapat, daun tunggal, bertangkai pendek, letaknya berhadapan bersilang, bulat telur sampai lanset, ujung dan pangkal runcing, tapi bergelombang, pertulangan menyirip, panjang $8-20 \mathrm{~cm}$, lebar $3-13 \mathrm{~cm}$, permukaan atas warnanya ungu mengilap [2].

Studi kandungan kimia Daun Hendeleum melaporkan bahwa ekstrak daun Handeleum memilki kandungan alkaloida yang tidak beracun, glikosida, steroida, fenol, polifenol, tannin, saponin, klorofil dan lendir. [2]. Penelitian [12] bahwa ekstrak etanol daun handeuleum mampu menghambat pertumbuhan bakteri E.coli yang menyebabkan penyakit diare dan mampu menghambat pertumbuhan bakteri S.aureus dan E.coli.

Daun Hendeleum merupakan satu dari ribuan tanaman obat yang berpotensi untuk dikembangkan menjadi obat herbal, maka pada penelitian ini kami akan melakukan penelitian tentang skrining fitokimia dan uji aktivitas bakteri E. Coli ATCC 25922 dan Pseudomonas aeruginosa secara invitro terhadap bagian daun Handeuleum (Graptophyllum pictum L. Griff.).Sampel Daun Hendeleum diperoleh dari daerah Langkat.Pertimbangannya secara topologi tanaman 
ini dapat tumbuh dengan mudah didaerah beriklim tropis. Perbedaan areal tumbuh tanaman, menjadi salah satu faktor penyebab perbedaan komposisi kandungan kimia daun Hendeleum. Hal ini disebabkan oleh perbedaan komposisi unsur kimia tanah.

\section{Metode}

\subsection{Bahan}

Bahan kimia yang digunakan bergrade analitik (pa : pro analisis) dari E.Merk. bahan kimia terdiri dari etil asetat, $\mathrm{NaOH}, \mathrm{KI}, \mathrm{n}$-heksan, dan lain sebagainya. Sampel tanaman yang digunakan adalah tumbuhan bangun-bangun (Coleus amboinicus Lour).Bagian tumbuhan yang digunakan adalah daun dan batang. Sampel diperoleh dari kabupaten Langkat Sumatera utara.Sampel tanaman diambil pada bulan Januari - Februari 2017

\subsection{Preparasi Sampel Tanaman}

Sampel tanaman dicuci bersih dan dikeringkan (air-dried) selama 5 hari pada suhu kamar (berkadar air 10\%). Sampel yang telah dikeringkan digiling halus menggunakan mortal hingga menjadi bubuk (berukuran 150 mesh) untuk selanjutnya dilakukan ekstraksi [7].

\subsection{Ekstraksi Sampel Tanaman}

$500 \mathrm{~g}$ bubuk sampel tanaman dimaserasi dengan pelarut etil asetat $70 \%$ dan n-heksan pada suhu kamar selama 24 jam. Proses tersebut diulang sebanyak 3 kali. Filtrat yang diperoleh di pekatkan dengan rotary evaporator sehingga diperoleh ektrak pekat [15].

\subsection{Ekstraksi Sampel Tanaman}

Skrining fitokimia dilakukan untuk identifikasi senyawa metabolit sekunder, terdiri dari alkaloid, flavonoid, terpenoid, saponin, steroid, dan tanin.

\subsubsection{Uji Alkaloid}

0,2 gr crude extract ditambah dengan $2 \mathrm{ml} \mathrm{H}_{2} \mathrm{SO}_{4}$ dan diaduk hingga homogen. Campuran reaksi tersebut difiltrasi.Filtrat yang diperoleh ditambah beberapa tetes reagenn Dragendrof's.Adanya pembentukan endapan Orange merah (Orange red Precipitate) mengindikasikan adanya senyawa alkaloid [17].

\subsubsection{Uji Flavonoid}

Beberapa tetes $\mathrm{HCl}$ p.a. ditambahkan kedalam sejumlah ekstrak sampel tanaman.Terbentuknya warna merah mengindikasikan adanya flavonoid [1].

\subsubsection{Uji Terpenoid}

$5 \mathrm{ml}$ ekstrak sampel ditambah dengan $2 \mathrm{ml}$ klorofom dan $3 \mathrm{ml} \mathrm{H}_{2} \mathrm{SO}_{4}$ p.a. terbentuknya cincin berwarna coklat kemerah-merahan (reddish brown) menunjukkan adanya terpenoid [1].

\subsubsection{Uji Saponin}

Uji Frothing (Frothing test) : 0,5 g ekstrak sampel dilarutkan dengan aquadest didalam tabung reaksi dan dikocok. Jika terbentuk busa menunjukkan adanya saponin [1].

Uji steroid dilakukan dengan reaksi Lieberman-Burchard : $2 \mathrm{ml}$ asetat anhidrat dan $2 \mathrm{ml} \mathrm{H}_{2} \mathrm{SO}_{4}$ p.a. ditambahkan kedalam $5 \mathrm{ml}$ ekstrak sampel. Perubahan warna dari violet menjadi biru menunjukkan adanya steroid [1]. 


\subsubsection{Uji Tanin}

0,2 gr ekstrak dimasukkan kedalam tabung reaksi, kemudian ditambah aquadest dan diaduk hingga homogen. Campuran dipanaskan didalam waterbath dan difiltrasi.Filtrat yang diperoleh ditambah dengan beberapa tetes Ferri klorida $\left(\mathrm{FeCl}_{3}\right)$.Pembentukan warna larutan hijau gelap (dark green) mengindikasikan adanya tannin [17].

\subsection{Uji Aktivitas Antimikroba}

Mikroorganisme yang digunakan didalam penelitian ini adalah Escheriachia coli ATCC 25922 dan Pseudomonas aeruginosa. Metode uji menggunakan metode difusi dinding sel (agar well diffusion method) [4][9]. Antibiotik standard yang digunakan adalah Amoxicillin.

\subsubsection{Penyediaan Media Nutrient Broth (NB)}

Sebanyak 8 gram media Nutrient Broth ditambahkan $1000 \mathrm{ml}$ aquades ke dalam labu Erlenmeyer, dicampur dan diaduk hingga rata, dipanaskan hingga mendidih dan larut. Kemudian dimasukkan ke dalam autoklaf pada suhu $121^{\circ} \mathrm{C}$ selama 15 menit, tunggu hingga agak dingin sekitar suhu $40-45^{\circ} \mathrm{C}$, kemudian masukkan ke dalam tabung reaksi [11].

\subsubsection{Penyediaan Media Nutrient Agar (NA)}

Nutrient Agar sebanyak 28 gram dimasukkan ke dalam labu Erlenmeyer, ditambahkan $1000 \mathrm{ml}$ aquades, dicampur dan diaduk hingga rata, dipanaskan hingga mendidih dan larut. Kemudian dimasukkan ke dalam autoklaf pada suhu $121^{\circ} \mathrm{C}$ selama 15 menit. Kemudian larutan yang ada di dalam labu Erlenmeyer dituang ke dalam cawan petri [5].

\subsubsection{Uji Aktivitas Antibakteri}

Lidi kapas steril dicelupkan di dalam biakkan kuman dari NB, kemudian lidi kapas diusapkan di permukaan media NA, prosedur tersebut diulang dua kali lagi dengan memutar plate $60^{\circ}$. Kemudian kertas cakram yang berdiameter $6 \mathrm{~mm}$ dicelupkan pada tabung yang berisi ekstrak sampel dengan konsentrasi $0 \mathrm{mg} / \mathrm{ml}, 50 \mathrm{mg} / \mathrm{ml}, 10$ $\mathrm{mg} / \mathrm{ml}, 15 \mathrm{mg} / \mathrm{ml}, 20 \mathrm{mg} / \mathrm{ml}$, dan $25 \mathrm{mg} / \mathrm{ml}$, kontrol positif dengan menggunakan antibiotik standardamoxicillin, ciprofloxacin dan cloramphenicoldan kontrol negatif dengan menggunakan aquades steril. Lalu kertas cakram yang berukuran $6 \mathrm{~mm}$ di letakkan pada permukaan media NA dengan bantuan pinset steril dengan sedikit penekanan agar kertas cakram melekat dengan baik, kemudian diinkubasi pada suhu $37^{\circ} \mathrm{C}$ selama 24 jam.Aktivitas antibakteri yang diuji dengan mengukur zona hambat yang terbentuk disekitar disk.Setiap perlakuan dilakukan dengan 3 kali perlakuan [9].

\subsubsection{Pengukuran Zona Hambat}

Pengukuran zona hambat yaitu dengan melihat zona hambat yang terdapat pada masing-masing disc pada setiap konsentrasi $(0 \mathrm{mg} / \mathrm{ml}, 50 \mathrm{mg} / \mathrm{ml}, 100 \mathrm{mg} / \mathrm{ml}, 150 \mathrm{mg} / \mathrm{ml}, 200 \mathrm{mg} / \mathrm{ml}$, dan $250 \mathrm{mg} / \mathrm{ml})$. Diameter zona hambat yang terbentuk diukur dengan jangka sorong dengan cara mengukur diamater vertikal dan horizontal menurut tes Kirbybaurier of Suspectibility.

\section{Hasil dan Pembahasan}

Skrining fitokimia merupakan analisa kualitatif terhadap ekstrak kasar daun Handeuleum (Graptophyllum pictum L. Griff.) untuk menentukan komposisi senyawa aktif ekstrak tersebut. Senyawa aktif yang dianalisa terdiri dari senyawa alkaloid, flavonoid, steroid, terpenoid, tanin, dan saponin. (tabel 3.1). 
Tabel 3.1.Hasil Skrining Fitokimia Ekstrak daun Handeuleum (Graptophyllum pictum L. Griff.)

\begin{tabular}{lllllll}
\hline \multirow{2}{*}{ Ekstrak Sampel } & \multicolumn{2}{l}{ Fitokimia } & & & \\
\cline { 2 - 6 } & Alkaloid & Flavonoid & Steroid & Terpenoid & Tanin & Saponin \\
\hline 1. Ekstrak etil asetat 70\% & + & + & + & + & + & + \\
2. Ekstrak n-Heksan & + & + & + & - & - & + \\
\hline
\end{tabular}

$(+)$ : ada ; (-) : tidak ada

Ekstrak daun Hendeleum memilki kompoisisi kimia, yang terdiri dari senyawa alkaloid, flavonoid, steroid, terpenoid, tanin, dan saponin, (tabel 3.1.) Ekstrak n-heksan daun Handeuleum (Graptophyllum pictum L. Griff.) terpenoid dan tanin tidak teridentifikasi. Metode ekstraksi didasarkan polaritas larutan. Komponen senyawa aktif daun Hendeuleum tertarik kuat dengan pelarut etil asetat dibandingkan dengan pelarut n-heksan. Hal ini mengindikasikan bahwa tingkat polaritas pelarut etil asetat sesuai dengan polaritas komponen kimia dari daun Hendeleuleum. Hasil skrining fitokimia (tabell 3.1), menunjukkan bahwa kemampuan pelarut etil asetat didalam mengikat senyawasenyawa aktif daun Hendeuleum lebih besar dibandingakan dengan pelarut n-heksan.

Keberadaan senyawa aktif tersebut sebagai petunjuk bahwa ekstrak daun Handeuleum (Graptophyllum pictum L. Griff.). memilki sifat bioaktivitas. Sifat bioaktivitas yang diuji berupa sifat antimikroba (tabel 3.2). Mikroba uji terdiri dari bakteri Pseudomonas aeruginosa (bakteri gram positif) dan strain bakteri Escherichia coli ATCC 25922 (bakteri gram negatif). Pengukuran aktivitas antimikroba dilakukan secara invitro. Metode pengukuranmenggunakan metode disk difusi. Metode disk fusi dilakukan berdasarkan pengukuran luas zona hambat yang terbentuk

Tabel 3.2. Diameter Zona Hambat Ekstrak Etil asetat 70\% Daun Handeuleum

\begin{tabular}{|c|c|c|c|c|c|c|c|c|}
\hline \multirow[t]{3}{*}{ No. } & \multirow[t]{3}{*}{ Mikroba Patogen } & \multicolumn{7}{|c|}{ Diameter Zona Hambat (mm) } \\
\hline & & \multicolumn{3}{|l|}{ Antibiotik } & \multicolumn{4}{|c|}{ Konsentrasi Ekstrak (\%) } \\
\hline & & Amoxicillin & 0 & 15 & 30 & 45 & 60 & 75 \\
\hline 1. & Pseudomonas aeruginosa & 1,0 & 0 & 9,0 & 12,8 & 15,6 & 18,2 & 20,6 \\
\hline 2. & Escherichia coli & 2,0 & 0 & 9,5 & 13,6 & 16,0 & 19,9 & 21,2 \\
\hline
\end{tabular}

Kemampuan daya hambat ekstrak etil asetat daun Hendeleum terhadap strain bakteri uji meningkat dengan adanya peningkatan konsentrasi ekstrak. Konsentrasi ekstrak berhubungan dengan kandungan senyawa aktif. Konsentrasi ekstrak yang tinggi akan memilki kandungan senyawa aktif yang tinggi pula. Kemampuan ekstrak berkonsentrasi tinggi menginhibisi aktivitas bakteri akan semakin meningkat bila dibandingkan dengan ekstrak berkonsentrasi rendah. Data ini menunjukkan adanya hubungan linier antara konsentrasi ekstrak dengan daya hambat ekstrak terhadap kerja mikroba.

Kemampuan daya hambat ekstrak etil asetat 70\% lebih tinggi terhadap strain bakteri E. Coli ATCC 25922 dibandingkan pada strain bakteri Pseudomonas aeruginosa. Hal ini dapat dilihat pada luas zona hambat yang dihasilkan. Zona hambat yang dihasilkan ekstrak etil asetat daun Hendeleum terhadap strain bakteri E. Coli ATCC 25922 berkisar 9,5 mm- 21,2 mm dan Pseudomonas aeruginosa berkisar 9,0 mm - 20,6 mm. kemampuan mikroba menginhibisi aktivitas bakteri berpengaruh terhadap luas zona hambat yang dihasilkan. Data ini (tabel 3.2) menunjukkan adanya hubungan linier antara daya hambat dengan luas zona hambat yang dihasil.

\section{Kesimpulan}

Kemampuan setiap pelarut untuk mengekstraksi senyawa-senyawa aktif dari suatu sampel tanamana berbeda. Perbedaan tersebut mengakibatkan kemampuan ekstrak untuk menginhibisi aktivitas mikroba juga akan berbeda. Ekstrak etil asetat $70 \%$ lebih kuat kemampuannya mengekstraski senyawa aktif (alkaloid, flavonoid, terpenoid, 
steroid, tanin, dan saponin) pada daun Hendeuleum dibandingkan dengan pelarut n-heksan. Perbedaan ini disebabkan perbedaan polaritas dari kedua pelarut tersebut.

\section{Ucapan Terima Kasih}

Penulis mengucapkan terima kasih kepada Laboratorium Kimia Universitas Medan Area, dan Universitas laboratorium Kimia bahan alam Universitas Sumatera Utara, atas fasilitas yang telah diberikan didalam menunjang pelaksanaan penelitian.

\section{Referensi}

[1] Abeer M. Ismail, E. A.-M.-F.-S. (2016). Preliminary Phytochemical Screening, Plant Growth Inhibition and Antimicrobial Activity Studies of Faidherbia albida legume Extracts. Jouenal of the Saudi Society of Agricultural Sciences , 112-117.

[2] Dalimartha, S. (1999). Atlas Tumbuhan Obat Indonesia. Jakarta: Trubus Agriwidya.

[3] Itoandon, E. O. (2012). Preliminary Phytochemical Analysis and Antimicrobial Properties of Crude Extract of Combretodendron macrocarpum Stem Bark. Nigerian Food Journal , 51-56.

[4] M.C. Mathabe, R. N. (2006). Antibacterial Activities of Medicinal Plants Used for the Treatment of Diarrhoea in Limpopo Province, South Africa. Journal of Ethnopharmacology, 286-293.

[5] Merck. (2005). Microbiologi Manual . Germany: Merck KGa A.

[6] Muhammad Bilal Sadiq, W. H. (2015). Screening of Phytochemicals and in Vitro evaluation of Antibacterial and Antioxidant Activities of Leaves, Pods, and Bark Extracts of Acacia nilotica (L.) Del. Industrial Crops and Products , 873-882.

[7] N. Prasannabalaji, G. M. (2012). Antibacterial Activities of Some Indian Traditional Plant Extracts. Asian Pacific Journal of Tropical Disease , 291-295.

[8] Neelam Gurnani, M. G. (2016). Chemical Composition, Total Phenolic and Flavonoid Contents, and in Vitro Antimicrobial and Antioxidant Activities of Crude Extracts from Red Chili Seeds (Capsicum frutescens L.). Journal of Taibah University for Science, 462-470.

[9] Noureddine Gherraf, A. Z. (2017). Chemical Constituents and Antimicrobial Activity of Essential Oils of Ammodaucus leucotricus. Arabian Journal of Chemistry, S2476-S2478.

[10] Prattipati Subhashini Devi, B. S. (2014). Phytochemical Screening for Secondary Metabolites in Boswellia serrata Roxb and Wrightia tinctoria (Roxb) R.Br. Notulae Scientia Biologicae , 474-477.

[11] Safitri, R. (2010). Medium Analisis Mikroorganisme (Isolasi dan Kultur). Jakarta : TIM.

[12] Sitompul, E. N. (2011). Aktivitas Antibakteri Dan Analisis Kandungan Kimia Daun Ungu (Graptophyllum pictum (L.) Griff.). Seminar Nasional Biologi, (pp. 263-268).

[13] Stephen J. Cavalieri, R. J. (2005). Manual of Antimicrobial Susceptibility Testing. Washington: American Society for Microbiology.

[14] Sunayana Nath, B. P. (2014). Phytochemical and Pharmacological Caharacteristics of Wrightiatinctoria : A Review. International Journal of Pure and Applied Sciences and Technology, 35-42.

[15] Syamsuddin Abdillah, R. M. (2015). Phytochemical Screening and Antimalaria Activity of Some Plants Traditionally Used in Indonesia. Asian Pacific Journal of Tropical Disease, 454-457.

[16] Umer Qadir, V. P. (2015). Preliminary Phytochemical Screening and in Vitro Antibacterial Activity of Anamirta cocculus (Linn.) Seed. Jurnal of King Saud University-Science, 97-104.

[17] Wisal Muhammad Khan, S. Z. (2016). Phytochemical Screening of Medicinal Plant : A Case Study of Selected Plant Species At Three Phenological Stages. Pack Journal Science, Ress , 243-252. 